\title{
Exploring Associations Between Self-Compassion, Self-Criticism, Mental Health, and Quality of Life in Adults with Cystic Fibrosis: Informing Future Interventions
}

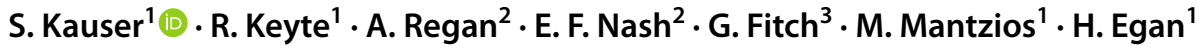

Accepted: 18 October 2021 / Published online: 8 November 2021

(c) The Author(s) 2021

\begin{abstract}
Self-compassion is increasingly recognised as an important and beneficial factor in quality of life and mental health-related research, but research within the adult cystic fibrosis (CF) population is scarce. In a cross-sectional study, 114 (56 female, 58 male) adults with CF completed and returned a series of validated questionnaires that assessed CF-related quality of life, negative emotional states (depression, anxiety and stress), self-compassion, and self-criticism. Quality of life and selfcompassion were positively correlated, and each in turn were inversely correlated with negative emotional states and selfcriticism. Negative emotional states correlated positively to self-criticism. Self-compassion and/or self-criticism moderated ten relationships between various sub-domains of quality of life and negative emotions. Psychological interventions that increase self-compassion may be beneficial for enhancing mental health and quality of life for adults with CF.
\end{abstract}

Keywords Cystic fibrosis $\cdot$ Self-compassion $\cdot$ Quality of life $\cdot$ Mental health $\cdot$ Self-criticism

\section{Introduction}

Cystic fibrosis $(\mathrm{CF})$ is a life-limiting and progressive genetic disorder that affected approximately 10,600 individuals within the United Kingdom (UK) during the year 2021 (Cystic Fibrosis Trust, 2021). Improvements in treatment, including the development of small molecule therapeutics that target the underlying defect, have resulted in many people with $\mathrm{CF}$ now surviving into later adulthood years (De Boeck, 2020). Even with these treatments, CF results in recurrent respiratory infections, pancreatic insufficiency, and reduced lung function due to progressive respiratory failure, which is the leading cause of death within the CF population (Goetz \& Ren, 2019).

S. Kauser

sophia.kauser@mail.bcu.ac.uk

1 Department of Psychology, Faculty of Business, Law and Social Sciences, Birmingham City University, Room C332, The Curzon Building, 4 Cardigan Street, Birmingham B4 7BD, UK

2 West Midlands Cystic Fibrosis Centre, University Hospitals Birmingham NHS Foundation Trust, Birmingham, UK

3 North West Midlands Cystic Fibrosis Centre, University Hospitals of North Midlands NHS Trust, Stoke-on-Trent, UK

\section{Mental Health and Quality of Life in CF Populations}

Despite improvements in life expectancy, people with CF continue to experience progressively worsening physical and psychological symptoms (Cronly et al., 2019a). Psychological comorbidities of depression and anxiety are extremely prevalent across the CF population (Quittner et al., 2014). Several studies have shown that mental health variables such as stress, anxiety, and depression are negatively linked with quality of life (Cronly et al., 2019a; Havermans et al., 2008; Platten et al., 2013; Riekert et al., 2007; Yohannes et al., 2012). Using the Cystic Fibrosis Quality of Life Questionnaire (CFQoL), anxiety and depression significantly correlated with physical functioning, social functioning, treatment issues, chest symptoms, emotional functioning, concerns for the future, interpersonal relationships, body image and career concerns (Yohannes et al., 2012).

In people with $\mathrm{CF}$, poor mental health is more strongly associated than poor physical health with lower quality of life, highlighting the importance of treating mental health to maintain quality of life. This is particularly important as physical challenges increase with age (Cronly et al., 2019a), and adults with CF may engage in health risk behaviours as a way of coping with their disease (Keyte et al., 2019a, b, 2020). The associations between positive mental health, 
better physical health, and higher health-related quality of life have been clearly demonstrated (Cronly et al., 2019b). With a projected $75 \%$ increase of the CF adult population by 2025 (Burgel et al., 2015), increased efforts to support both psychological and physical health needs in the later adulthood years are required.

\section{Self-Compassion}

Self-compassion is an important and beneficial resource for supporting mental health and quality of life for adults with CF. Self-compassion is defined as the act of being open to one's own suffering by implementing a kind, understanding and non-judgemental approach towards challenges (Neff, 2003a, b). Neff specified three positive and core elements of self-compassion, which include self-kindness, common humanity, and mindfulness, and three negative elements including self-judgement, isolation, and over-identification. In both clinical and non-clinical populations, higher selfcompassion levels have been associated with better ability to cope with pain, increased well-being in later adulthood years, adaptive responses to illness, and increased engagement in health-promoting behaviours (Allen et al., 2012; Egan \& Mantzios, 2018; Egan et al., 2019; Mantzios \& Egan, 2017; Sirois et al., 2015). Research in self-compassion and mental health over the past decade indicated a large effect size for the relationship between both concepts, linking increased levels of self-compassion with fewer symptoms of depression, anxiety, and stress amongst non-CF populations (MacBeth \& Gumley, 2012). Self-criticism, which can be conceptualised as opposite to self-compassion, is described as engaging in a constant and harsh evaluation of oneself (Blatt \& Zuroff, 1992). Self-criticism has been negatively associated with quality of life and positively associated with depression, anxiety, and stress (Iancu et al., 2015; Pinto-Gouveia et al., 2014; Priel \& Shahar, 2000; Zhang et al., 2019). Research in both self-compassion and self-criticism may offer an insight as to which psychological interventions are most valuable for people with CF.

Psychological interventions and therapies that draw upon the foundations of self-compassion, including lovingkindness meditation (LKM), compassion-focussed therapy (CFT), and mindful self-compassion (MSC) training, have been successful in promoting positive health outcomes (Gilbert, 2009; Ilies et al., 2019; Neff \& Germer, 2013; Salzberg, 1995). The theoretical connectedness between mindfulness and self-compassion suggests that both concepts provide key elements to these interventions. MacBeth and Gumley (2012) highlighted the use of compassion-based therapies to reduce psychological distress through the acquisition of an open and compassionate attitude, whereby the individual's relationship with their challenges are reformed, resulting in the development of a healthier relationship with oneself.
Previous literature demonstrated that self-compassion and mindfulness-based interventions are beneficial in reducing anxiety, depression, and stress symptoms, decreasing selfcriticism and improving quality of life (Chiesa \& Serretti, 2009; Evans et al., 2008; Godfrin \& Van Heeringen, 2010; Segal et al., 2002; Shahar et al., 2015).

\section{Self-Compassion: A Construct Relevant to Quality of Life and Mental Health in Adults with CF}

Prior work on self-compassion in non-CF populations suggests that self-compassion could help people cope with the multiple challenges of living with CF that have been shown to affect quality of life, including physical health, body image, treatment burden, future concerns, and employment (Brion et al., 2014; Herriot \& Wrosch, 2020; Phillips, 2018; Seekis et al., 2017; Rajabi \& Ghezelsefloo, 2020). Individuals with CF face extensive physical health challenges and symptomatology including coughing, breathlessness, and pain (Stenekes et al., 2009). People with CF often experience pulmonary exacerbations, characterised by changes in cough, sputum production, dyspnoea, and decreases in energy level, appetite, and weight loss, resulting in increased emotional distress (de Boer et al., 2011; Goss \& Burns, 2007; Schmid-Mohler et al., 2019). One recent study showed that self-compassion predicted lower levels of daily physical symptoms as well as fewer rises in chronic illness amongst people in advanced old age (Herriot \& Wrosch, 2020), suggesting that self-compassion may be a useful tool in supporting physical health in adults with CF particularly when approaching end of life.

Body image perception is relevant within the $\mathrm{CF}$ literature as weight maintenance can present continuous difficulties for people with $\mathrm{CF}$, negatively affecting psycho-social functioning (Egan et al., 2020). A critical aspect of CF patient care involves the monitoring of body mass index (BMI). Patients with $\mathrm{CF}$ who received enteral tube feeding reported lower self-esteem, a poorer quality of life, and less satisfaction with their body image (Abbott et al., 2007). In a non-CF population, low levels of self-compassion have been found to mediate the relationship between body image disturbance and psychological distress (Przezdziecki et al., 2013). Similarly, a study exploring the effectiveness of a self-compassion writing task revealed the self-compassion writing group showed higher post-treatment body appreciation when compared to self-esteem and control groups (Seekis et al., 2017). The findings by Przezdziecki et al. (2013) and Seekis et al. (2017) provide promising evidence for the role of selfcompassion for people at risk of experiencing body image disturbance.

$\mathrm{CF}$ treatment regimens are extremely burdensome (Knudsen et al., 2016) with detrimental impacts on both quality of life and psychological well-being (Sawicki \& Goss, 2015), 
and low adherence is a major concern (Keyte et al., 2017). The benefits of self-compassion have not been thoroughly explored within the CF population for possible positive associations with treatment-related challenges. However, in a sample of patients diagnosed with HIV, results highlighted associations between self-compassion and better medical and treatment adherence, as well as lower levels of stress and anxiety (Brion et al., 2014). Therefore, understanding more about self-compassion in CF may prove beneficial for this population.

Having CF understandably raises concerns for the future, and people with high levels of concerns have increased levels of anxiety and stress (Yohannes et al., 2012). People with higher self-compassion have a more positive future outlook (Phillips, 2018) and use more adaptive coping mechanisms such as cognitive restructuring when considering future suffering (Allen \& Leary, 2010). Challenges in employment and financial insecurity for people with $\mathrm{CF}$ add to concerns for the future (Havermans et al., 2009); having higher selfcompassion can reduce job stress and increase job-related well-being (Rajabi \& Ghezelsefloo, 2020). Self-compassion interventions may therefore be valuable for increasing employment-related affective well-being as well as reducing employment-related stress in adults with CF.

\section{Rationale, Aims, and Hypothesis}

Self-compassion is increasingly recognised as an important factor in quality of life and mental health research. It is therefore important that we understand more about how self-compassion could be integrated into both clinical care and self-care within the adult CF population. It is possible that any benefits of mindfulness for people with CF may also be observed in self-compassion and compassion-based interventions (Egan \& Mantzios, 2016; Mantzios \& Egan, 2016; Mantzios et al., 2016). Thus, the current research aimed to firstly explore the relationships between quality of life, negative emotional states (depression, anxiety, and stress), selfcompassion, and self-criticism and secondly to explore the moderating effects of self-compassion and self-criticism on the relationship between quality of life and negative emotional states within an adult CF population.

We predicted that a negative correlation would be observed between negative emotional states and quality of life. We also predicted that self-compassion would be associated with increased quality of life and decreased negative emotional states, and that self-criticism would result in correlations in the opposite direction. Additionally, we hypothesised that self-compassion would moderate the relationship between negative emotions and quality of life. Similarly, we hypothesised that self-criticism would moderate relationships between negative emotional states and quality of life.

\section{Method}

\section{Participants}

We recruited 160 English-speaking adults living in the UK who had a confirmed diagnosis of CF. Of these, 114 participants ( $71 \%$ response rate) completed and returned the questionnaires. Participant demographic and medical data are presented in Table 1. Recruitment took place at two regional adult CF Centres in the Midlands over a period of 8 months on pre-arranged days for data collection, using a purposeful sampling method. Participant invitations to take part in the study occurred during a routine outpatient appointment or after inpatient admission to the ward. Ethical approval was obtained by the Universities Ethical Committee, the Health Research Authority (HRA) via an

Table 1 Participant demographic and medical data

\begin{tabular}{ll}
\hline Variable & Participants $(n=114)$ \\
\hline Gender & \\
Male & 58 \\
Female & 56 \\
Age (years) & \\
Range & $18-70$ \\
Mean (SD) & $32.36(11.50)$ \\
Ethnicity & \\
White & 100 \\
Asian or Asian British & 8 \\
Mixed & 5 \\
Cypriot & 1 \\
Highest level of education & \\
University degree & 52 \\
A levels or BTEC & 41 \\
GCSE & 18 \\
Not applicable & 3 \\
Current employment status & \\
Employed & \\
Self-employed & 65 \\
Un-employed & 12 \\
Retired & $28.79-123(19.65)$ \\
BMI & \\
Range & \\
Mean (SD) & \\
FEV $(\%)$ & \\
Range & \\
Mean (SD) & \\
FVC (\%) & \\
Range & \\
Mean (SD) & \\
\hline & \\
&
\end{tabular}


NRES Committee (REC reference: 19/NE/0183), and the $\mathrm{R} \& \mathrm{D}$ departments at each research site.

\section{Materials}

\section{Demographic Information Form}

Participants reported their date of birth, gender, ethnicity, highest level of education, and employment status.

\section{Medical Information Form}

We collected the following information from participants' medical records: forced expiratory volume in 1 second $\left(\mathrm{FEV}_{1}\right)$, forced vital capacity (FVC) and BMI.

\section{Self-Compassion Scale (SCS; Neff, 2003a)}

The SCS is a 26-item measure composed of six subscales: self-kindness, self-judgement, common humanity, isolation, mindfulness, and over-identification. Possible responses range from 1 (almost never) to 5 (almost always). Total scores were computed following the calculation of a total mean, as recommended by Neff (2003a). Higher scores indicate a greater amount of self-compassion. Sample items include "I'm kind to myself when I'm experiencing suffering" (subscale: selfkindness) and "when I fail at something important to me I become consumed by feelings of inadequacy" (subscale: overidentification). The SCS demonstrated good internal consistency, test-retest reliability, and convergent validity in clinical populations (Castilho et al., 2015). In the present sample, Cronbach's alpha for the total score was .94.

\section{The Functions of Self-Criticizing/Attacking Scale (FSCS; Gilbert et al., 2004)}

The FSCS is a 21-item measure composed of two subscales: self-correction and self-persecution. Possible responses range from 0 (not at all like me) to 4 (extremely like me). Higher scores indicate a greater amount of self-criticism. Sample items include "I get critical and angry with myself to keep myself in check" (subscale: self-correction) and "I get critical and angry with myself because, if I punish myself I feel better" (subscale: self-persecution). Gilbert et al. (2004) conducted a principal components analysis and reported good internal consistency for the FSCS scale components. In the present sample, Cronbach's alpha was .89.

\section{The Depression Anxiety Stress Scale (DASS; Lovibond \& Lovibond, 1995)}

The DASS is a 21-item measure composed of three subscales: depression, anxiety, and stress. Possible responses range from 0 (did not apply to me at all) to 3 (applied to me very much, or most of the time). Total scores were computed following the scores multiplied by two, as recommended by Lovibond and Lovibond (1995). Higher scores indicate a greater severity of negative emotional states of depression, anxiety, and stress. Sample items include "I felt that life was meaningless" (subscale: depression) and "I felt scared without any good reason" (subscale: anxiety). The DASS demonstrated internal consistency and concurrent validity in the acceptable to excellent ranges in clinical populations (Antony et al., 1998). In the present sample, Cronbach's alpha for the total score was .95 .

\section{CFQoL; Gee et al. (2000)}

The CFQoL is a 52-item measure composed of nine subscales: physical functioning (1), social functioning (2), treatment issues (3), chest symptoms (4), emotional functioning (5), concerns for the future (6), interpersonal relationships (7), body image (8) and career concerns (9). Possible responses for scales one to four range from 1 (all of the time) to 6 (never), whilst scales five to nine range from 1 (strongly agree) to 6 (strongly disagree). Higher scores indicate a greater level of quality of life. Sample items include "The way that my CF has made me look because of my height/weight makes life less enjoyable" (subscale: body image) and "During the last two weeks, my CF has made me feel lacking in energy" (subscale: physical functioning). The CFQoL showed robust internal reliability, concurrent validity and test-retest reliability in a clinical CF population (Gee et al., 2000). In the present sample, Cronbach's alpha for the overall score was .97.

\section{Procedure}

Following the "consent to contact" ethical procedure, a clinician at the CF centre introduced the research study to the potential participant. If agreed, the first author then provided potential participants with a verbal overview of what the study entailed, followed by a participant information form. Once verbally agreed, participants provided written informed consent and then complete the demographics form and the questionnaires. On average, the questionnaires took 20 minutes to complete. The first author collected data from participants' medical records $\left(\mathrm{FEV}_{1}\right.$, FVC, BMI). Following completion, the first author issued participants with a debrief form with an overview of the study and researchers contact details should participants decide to withdraw their data later, though none did so. 


\section{Analyses}

We used IBM SPSS v25 to analyse the data. Preliminary analyses examined for outliers and met assumptions of normality and linearity (Field, 2013). We computed bivariate correlations to explore associations between self-compassion, self-criticism, negative emotional states, and quality of life. Moderation analyses further examined whether selfcompassion or self-criticism moderated the relationship between negative emotional states and quality of life total scores and subscale scores. We used PROCESS v3.5 (Model 1) to interpret moderation effects which included a bootstrap sample of 10,000 , and variables centred to their means (Hayes, 2017). Calculations of simple effects coefficients for three values of the moderator included: 1 SD below the mean, at the mean, and $1 \mathrm{SD}$ above the mean. Bias-corrected confidence intervals $(\mathrm{CI})$ and the bootstrapping procedure were used to attribute statistical significance of the moderator. To reduce Type I error, the research team applied a Bonferroni correction procedure for multiple hypothesis testing using a correction applied to the alpha level (Field, 2013). The alpha level (0.05) was divided by the number of tests conducted within self-compassion and self-criticism moderation analyses.

\section{Results}

Pearson correlation coefficients between quality of life (CFQoL), negative emotional states (DASS), self-compassion (SCS), and self-criticism (FSCS) total scores are presented in Table 2.

Pearson correlation coefficients between quality of life, negative emotional states, self-compassion and self-criticism subscale scores are presented in Table 3 . We found negative associations between all nine CFQoL subscales and all three DASS subscales (depression, anxiety, and stress).

Further analyses of moderation effects explored selfcompassion and self-criticism as potential moderators of

Table 2 Bivariate correlations between quality of life, negative emotional states, self-compassion, and self-criticism total scores

\begin{tabular}{lllll}
\hline & 1 & 2 & 3 & 4 \\
\hline 1. CFQoL & - & & & \\
2. DASS & $-.639^{* *}$ & - & & \\
3. SCS & $.526^{* *}$ & $-.697^{* *}$ & - & \\
4. FSCS & $-.552^{* *}$ & $.575^{* *}$ & $-.636^{* *}$ & - \\
\hline
\end{tabular}

CFQoL Cystic Fibrosis Quality of Life Scale, DASS Depression Anxiety Stress Scale, SCS Self-Compassion Scale, FSCS Functions of Self-Criticizing/Attacking Scale

**Correlation is significant at the .01 level observed relationships between quality of life and negative emotional states (see Table 4).

Average and high levels of self-compassion significantly and negatively moderated the relationship between body image and anxiety. People who felt more positive about their body image had lower levels of anxiety when self-compassion moderated the relationship at average and high levels (see Table 4 and Fig. 1).

Average and high levels of self-compassion also significantly and negatively moderated the relationship between treatment issues and anxiety. People who reported fewer treatment-related issues had lower levels of anxiety when self-compassion moderated the relationship at average and high levels (see Table 4 and Fig. 1).

Low and average levels of self-criticism significantly and negatively moderated the relationship between career issues and stress. Participants who reported more positive career issues had lower levels of stress when self-criticism moderated the relationship at low and average levels (see Table 4 and Fig. 2).

Using a Bonferroni adjusted alpha level of 0.025 for selfcompassion moderations, the relationships between body image and anxiety $(p=.011)$ and treatment issues and anxiety $(p=.009)$ remained significant. However, when using a Bonferroni adjusted alpha level of 0.017 for self-criticism moderations, only the relationship between career issues and stress $(p=.007)$ remained significant. Both relationships between treatment issues and anxiety $(p=.026)$, and chest symptoms and anxiety $(p=.076)$ became insignificant after the Bonferroni correction.

Moderation analyses for self-compassion and self-criticism subscales are available from the author on request.

\section{Discussion}

We aimed to explore relationships between quality of life, negative emotional states, self-compassion, and self-criticism, including the moderating role of self-compassion and self-criticism within an adult CF population. Individuals who endorsed better quality of life tended to report greater self-compassion, whereas those who reported more severe negative emotional states endorsed greater self-criticism. Further investigation of moderation effects suggested that self-compassion or self-criticism moderated three relationships between quality of life and negative emotional states.

Our findings on the relationships between quality of life and mental health align with previous findings in this population (Cronly et al., 2019a; Havermans et al., 2008; Platten et al., 2013; Riekert et al., 2007; Yohannes et al., 2012). Literature on self-compassion and self-criticism within the adult CF population has been largely unexplored. The present results demonstrate positive associations between 


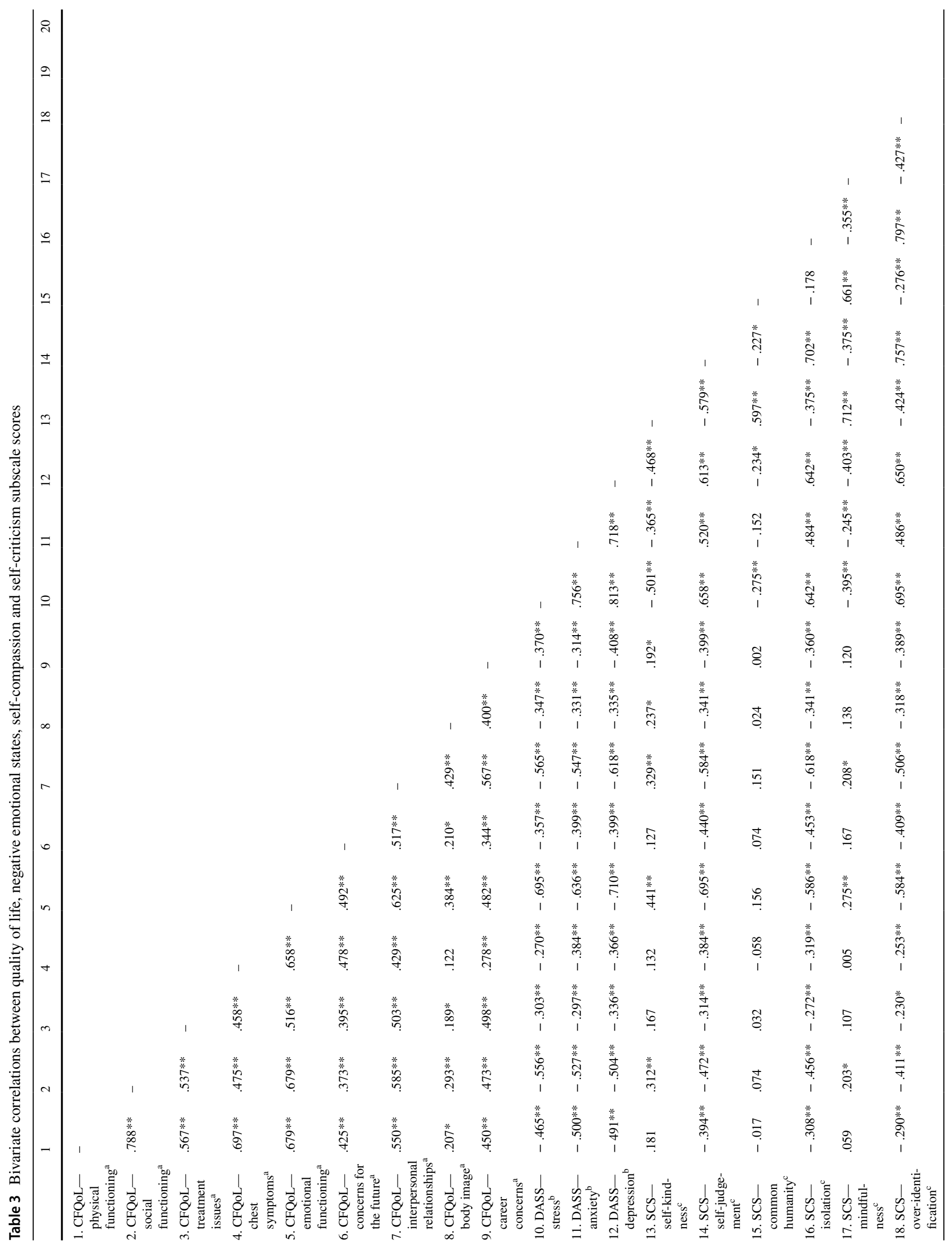




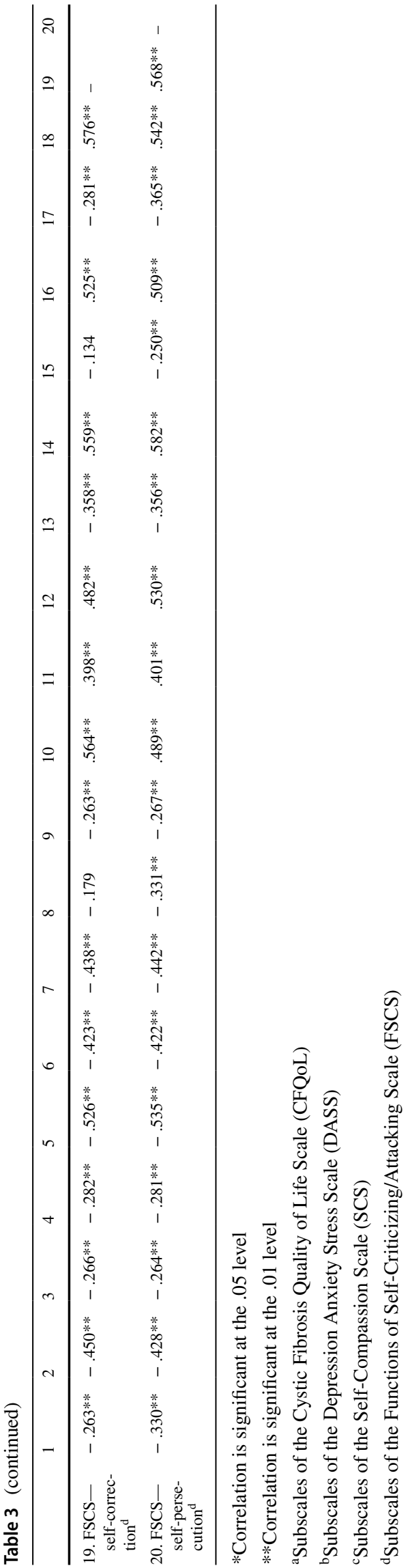

increased self-compassion, negative emotional states, and enhanced levels of quality of life in adults with $\mathrm{CF}$, which corroborates with prior self-compassion studies in non-CF populations (MacBeth \& Gumley, 2012; Pinto-Gouveia et al., 2014). Both the current study and previous findings report associations between increased levels of self-criticism with higher levels of negative emotional states and quality of life (Pinto-Gouveia et al., 2014; Iancu et al., 2015).

\section{Self-Compassion as a Moderator of the Relationship Between Quality of Life Domains and Anxiety}

The present study suggests that self-compassion may moderate the association of body image concerns with anxiety in people with CF. As body image perception related to weight maintenance and tube feeding negatively affects psychosocial functioning for adults with CF (Abbott et al., 2007; Egan et al., 2020), promoting accessible and effective ways to increase self-compassion could prove beneficial. Psychological practices such as loving-kindness meditation, a selfcare technique to boost well-being and self-acceptance, and compassion-focussed therapy centring on expanding selfcompassionate qualities and skills may be helpful for people who report lower quality of life relating to body image concerns.

We also found that self-compassion also moderated the relationship between treatment issues and anxiety. Both the current study and previous literature demonstrate the impact of CF treatment burden upon psychological wellbeing (Sawicki \& Goss, 2015). Self-compassionate people recognise that experiencing life difficulties is inevitable and accept this reality with self-kindness rather than self-judgement when confronted with painful experiences (Neff, 2003a). Thus, self-compassion may be an important resource for adults with $\mathrm{CF}$ when experiencing challenging periods in life (for example, during a health or lung function decline which can exacerbate treatment issues). Treatment regimens form a significant part of daily life for people with CF (Knudsen et al., 2016). Focussing on increasing levels of self-compassion with mindful self-compassion training could reduce the psychological impact of changes in healthrelated quality of life.

\section{Limitations and Future Research}

We identified three limitations within this study. The first limitation is that the study did not account for whether or 
Table 4 Conditional effects of self-compassion and selfcriticism scores on relationships between quality of life and negative emotional state domains

\begin{tabular}{|c|c|c|c|c|c|c|}
\hline Relationship & Moderator & & $\beta$ & $p$ & $95 \% \mathrm{CI}$ & \\
\hline \multirow[t]{3}{*}{ CFQoL-body image and DASS-anxiety } & \multirow[t]{3}{*}{ SCS } & $-1 S D$ & -.046 & .378 & -.150 & .057 \\
\hline & & At the mean & -.116 & .011 & -.205 & -.027 \\
\hline & & $+1 S D$ & -.185 & .008 & -.322 & -.049 \\
\hline \multirow[t]{3}{*}{ CFQoL-treatment issues and DASS-anxiety } & \multirow[t]{3}{*}{ SCS } & $-1 S D$ & -.012 & .809 & -.114 & .089 \\
\hline & & At the mean & -.099 & .009 & -.174 & -.025 \\
\hline & & $+1 S D$ & -.186 & .002 & -.305 & -.068 \\
\hline \multirow[t]{3}{*}{ CFQoL-career issues and DASS-stress } & \multirow[t]{3}{*}{ FSCS } & $-1 S D$ & -.174 & .000 & -.267 & -.080 \\
\hline & & At the mean & -.094 & .007 & -.160 & -.027 \\
\hline & & $+1 S D$ & -.014 & .792 & -.115 & .088 \\
\hline
\end{tabular}

CFQoL Cystic Fibrosis Quality of Life Scale, DASS Depression Anxiety Stress Scale, SCS Self-Compassion Scale (total score), FSCS Functions of Self-Criticizing/Attacking Scale (total score) not individuals had ever engaged in any self-compassion or mindfulness-based interventions. The second limitation involved a lack of control for mental health diagnosis and medication use. Addressing these two limitations would have allowed for stronger conclusions to be drawn. Thirdly, the study presents cross-sectional data which, while a necessary first step in identifying relationships between the variables, makes it difficult for causal associations to be interpreted. Future research should therefore explore the effects of self-compassion on quality of life and mental health in adults with CF through psychological interventions which draw upon self-compassion and mindfulnessbased concepts. Given the physical respiratory difficulties faced by individuals with CF, researchers should consider the type of intervention administered to facilitate the needs of this population. For example, practises that rely heavily upon focussed breathing may prove particularly difficult for individuals with $\mathrm{CF}$.

\section{Conclusion}

We found that quality of life, negative emotional states, selfcompassion, and self-criticism were all significantly associated, and that self-compassion and self-criticism moderate the relationship between negative emotional states subscales and five quality of life subscales. Understanding the elements of self-compassion and mindfulness in adults with CF may be useful in developing future interventions that will continue to support the psychological and physical health needs of this population. The current findings suggest that psychological interventions which increase self-compassion could be beneficial for enhancing better mental health and quality of life for adults with CF. 


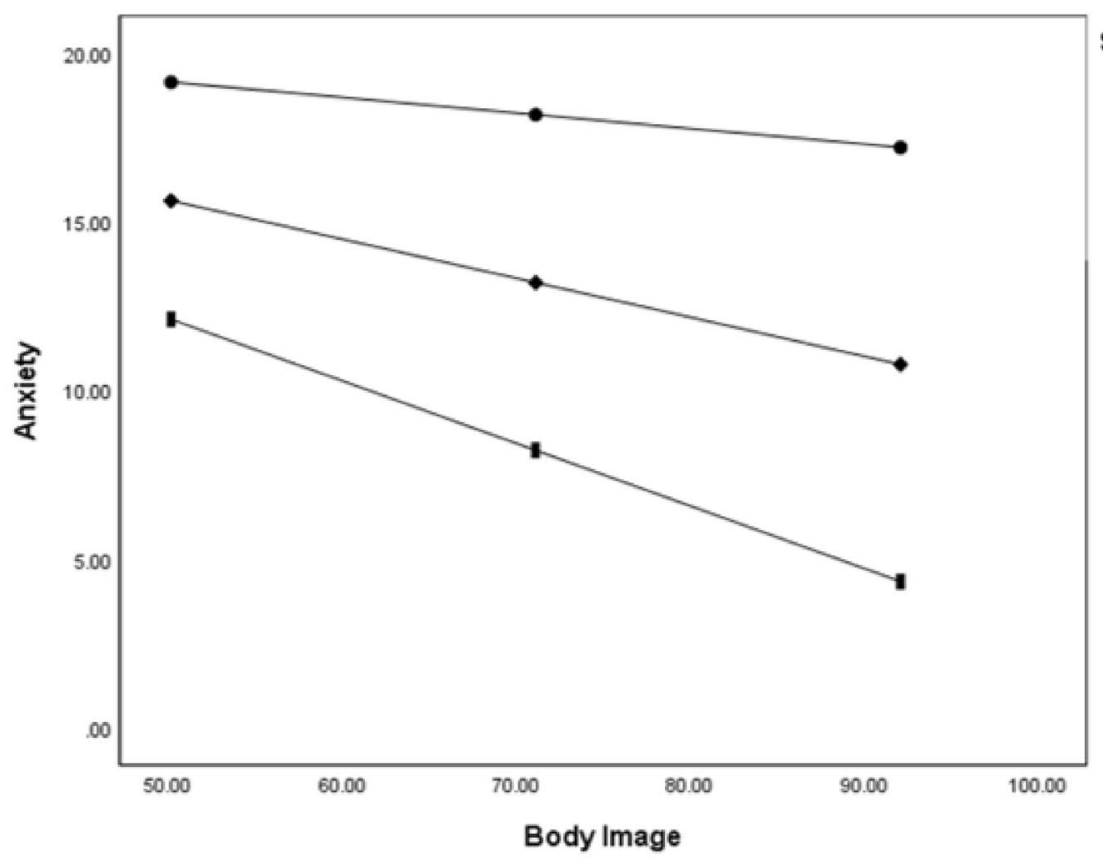

Self-Compassion

- Low

- Average

I High

(A)

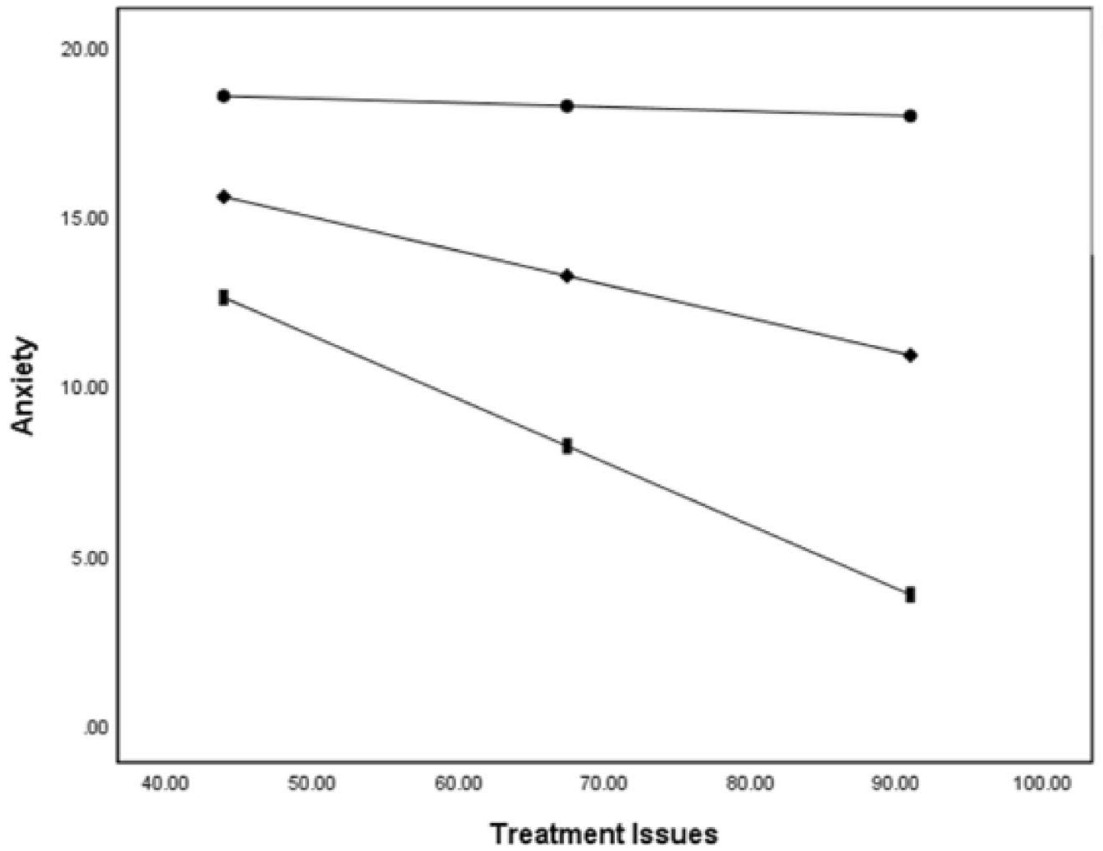

Self-Compassion

- Low

- Average

1 High

(B)

Fig. 1 Self-Compassion as a moderator of the relationship between DASS-anxiety scores and quality of life domain scores $(\mathrm{A}=$ Body Image, B = Treatment Issues). Lines depict modelled relationships at different levels of the Self-Compassion Scale (total score): $1 S D$ below the mean of SCS (Low), mean SCS (Average), and $1 S D$ above the mean of SCS (High) 


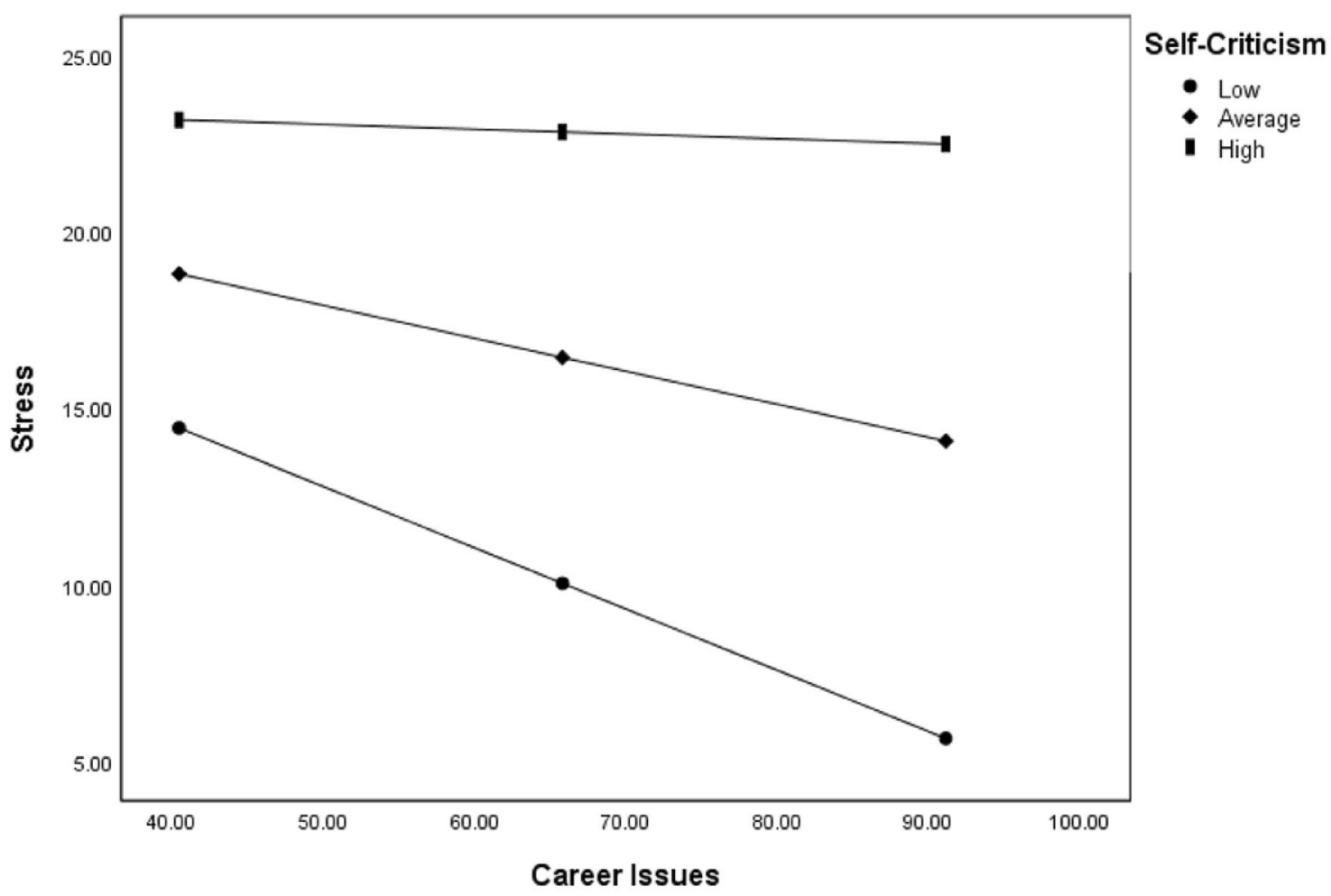

Fig. 2 Self-Compassion as a moderator of the relationship between DASS-stress scores and quality of life domain scores. Lines depict modelled relationships at different levels of the Self-Compassion

Author Contributions SK, HE, MM, and RK designed the study. SK collected data, conducted data analyses, and wrote the manuscript. HE, RK, MM, AR, EFN, and GF supported the study and HE, MM, and EFN critically reviewed the manuscript. All authors gave their final approval of the manuscript.

Funding No funds, grants, or other support were received.

Data Availability The data that support the findings of this study are available on request from the corresponding author. The data are not publicly available due to public availability violating the consent that was given by research participants.

Code Availability Not applicable.

\section{Declarations}

Conflict of interest S. Kauser, R. Keyte, A. Regan, E. F. Nash, G. Fitch, M. Mantzios, and H. Egan have no conflicts of interest to declare that are relevant to the content of this article.

Ethical Approval The study was approved by the Ethical Review Board of the University, the Health Research Authority (HRA), and with the 1964 Helsinki Declaration and its later amendments.

Research Involving Human and Animal Participants This manuscript does not contain any studies with animals.
Scale (total score): $1 S D$ below the mean of SCS (Low), mean SCS (Average), and $1 S D$ above the mean of SCS (High)

Consent to Participate Informed written consent was obtained from all individual participants prior to participation.

Consent for Publication The authors affirm that participants provided informed consent for publication.

Open Access This article is licensed under a Creative Commons Attribution 4.0 International License, which permits use, sharing, adaptation, distribution and reproduction in any medium or format, as long as you give appropriate credit to the original author(s) and the source, provide a link to the Creative Commons licence, and indicate if changes were made. The images or other third party material in this article are included in the article's Creative Commons licence, unless indicated otherwise in a credit line to the material. If material is not included in the article's Creative Commons licence and your intended use is not permitted by statutory regulation or exceeds the permitted use, you will need to obtain permission directly from the copyright holder. To view a copy of this licence, visit http://creativecommons.org/licenses/by/4.0/.

\section{References}

Abbott, J., Morton, A. M., Musson, H., Conway, S. P., Etherington, C., Gee, L., ... \& Webb, A. K. (2007). Nutritional status, perceived body image and eating behaviours in adults with cystic fibrosis. Clinical Nutrition, 26(1), 91-99. https://doi.org/10.1016/j.clnu. 2006.08.002 
Allen, A. B., Goldwasser, E. R., \& Leary, M. R. (2012). Self-compassion and well-being among older adults. Self and Identity, 11, 428-453. https://doi.org/10.1080/15298868.2011.595082

Allen, A. B., \& Leary, M. R. (2010). Self-compassion, stress, and coping. Social and Personality Psychology Compass, 4, 107-118. https://doi.org/10.1111/j.1751-9004.2009.00246.x

Antony, M. M., Bieling, P. J., Cox, B. J., Enns, M. W., \& Swinson, R. P. (1998). Psychometric properties of the 42 -item and 21 -item versions of the depression anxiety stress scales in clinical groups and a community sample. Psychological Assessment, 10, 176. https:// doi.org/10.1037/1040-3590.10.2.176

Blatt, S. J., \& Zuroff, D. C. (1992). Interpersonal relatedness and self-definition: Two prototypes for depression. Clinical Psychology Review, 12, 527-562. https://doi.org/10.1016/0272-7358(92)90070-O

Brion, J. M., Leary, M. R., \& Drabkin, A. S. (2014). Self-compassion and reactions to serious illness: The case of HIV. Journal of Health Psychology, 19, 218-229. https://doi.org/10.1177/13591 05312467391

Burgel, P. R., Bellis, G., Olesen, H. V., Viviani, L., Zolin, A., Blasi, F., \& Elborn, J. S. (2015). Future trends in cystic fibrosis demography in 34 European countries. European Respiratory Journal, 46, 133-141. https://doi.org/10.1183/09031936.00196314

Castilho, P., Pinto-Gouveia, J., \& Duarte, J. (2015). Evaluating the multifactor structure of the long and short versions of the selfcompassion scale in a clinical sample. Journal of Clinical Psychology, 71, 856-870. https://doi.org/10.1002/jclp.22187

Chiesa, A., \& Serretti, A. (2009). Mindfulness-based stress reduction for stress management in healthy people: A review and meta-analysis. The Journal of Alternative and Complementary Medicine, 15, 593-600. https://doi.org/10.1089/acm.2008.0495

Cronly, J. A., Duff, A. J., Riekert, K. A., Fitzgerald, A. P., Perry, I. J., Lehane, E. A., ... Savage, E. (2019a). Health-related quality of life in adolescents and adults with cystic fibrosis: Physical and mental health predictors. Respiratory Care, 64, 406-415. https://doi.org/ 10.4187/respcare.06356

Cronly, J., Duff, A., Riekert, K., Horgan, A., Lehane, E., Perry, I., ... Savage, E. (2019b). Positive mental health and wellbeing in adults with cystic fibrosis: A cross sectional study. Journal of Psychosomatic Research, 116, 125-130. https://doi.org/10. 1016/j.jpsychores.2018.11.016

Cystic Fibrosis Trust. (2021). Cystic Fibrosis FAQs. Retrieved 4 October 2021, from, https://www.cysticfibrosis.org.uk/what-is-cysticfibrosis/faqs

De Boeck, K. (2020). Cystic fibrosis in the year 2020: A disease with a new face. Acta Paediatrica, 109, 893-899. https://doi.org/10. 1111/apa.15155

de Boer, K., Vandemheen, K. L., Tullis, E., Doucette, S., Fergusson, D., Freitag, A., ... Aaron, S. D. (2011). Exacerbation frequency and clinical outcomes in adult patients with cystic fibrosis. Thorax, 66, 680-685. https://doi.org/10.1136/thx.2011.161117

Egan, H., Keyte, R., McGowan, K., Peters, L., Lemon, N., Parsons, S., ... Mantzios, M. (2019). 'You before me': A qualitative study of health care professionals' and students' understanding and experiences of compassion in the workplace, self-compassion, self-care and health behaviours. Health Professions Education, 5, 225-236. https://doi.org/10.1016/j.hpe.2018.07.002

Egan, H., Keyte, R., Nash, E. F., Barrett, J., Regan, A., \& Mantzios, M. (2020). Mindfulness moderates the relationship between emotional eating and body mass index in a sample of people with cystic fibrosis. Eating and Weight Disorders-Studies on Anorexia, Bulimia and Obesity. https://doi.org/10.1007/s40519-020-00969-6

Egan, H., \& Mantzios, M. (2016). Mindfulness and mindful eating: Reflections on how individuals with cystic fibrosis may benefit. Eating and Weight Disorders-Studies on Anorexia, Bulimia and Obesity, 21, 511-512. https://doi.org/10.1007/ s40519-016-0255-y
Egan, H., \& Mantzios, M. (2018). A qualitative exploration of selfkindness and "treating oneself" in contexts of eating, weight regulation and other health behaviors: Implications for mindfulness-based eating programs. Frontiers in Psychology, 9, 880. https://doi.org/10.3389/fpsyg.2018.00880

Evans, S., Ferrando, S., Findler, M., Stowell, C., Smart, C., \& Haglin, D. (2008). Mindfulness-based cognitive therapy for generalized anxiety disorder. Journal of Anxiety Disorders, 22, 716-721. https://doi.org/10.1016/j.janxdis.2007.07.005

Field, A. (2013). Discovering statistics using IBM SPSS statistics. Sage.

Gee, L., Abbott, J., Conway, S. P., Etherington, C., \& Webb, A. K. (2000). Development of a disease specific health related quality of life measure for adults and adolescents with cystic fibrosis. Thorax, 55, 946-954. https://doi.org/10.1136/thorax.55.11.946

Gilbert, P. (2009). Introducing compassion-focused therapy. Advances in Psychiatric Treatment, 15, 199. https://doi.org/10. 1192/apt.bp.107.005264

Gilbert, P., Clarke, M., Hempel, S., Miles, J. N., \& Irons, C. (2004). Criticizing and reassuring oneself: An exploration of forms, styles and reasons in female students. British Journal of Clinical Psychology, 43, 31-50. https://doi.org/10.1348/0144665047 72812959

Godfrin, K. A., \& Van Heeringen, C. (2010). The effects of mindfulness-based cognitive therapy on recurrence of depressive episodes, mental health and quality of life: A randomized controlled study. Behaviour Research and Therapy, 48, 738-746. https://doi. org/10.1016/j.brat.2010.04.006

Goetz, D., \& Ren, C. L. (2019). Review of cystic fibrosis. Pediatric Annals, 48, e154-e161. https://doi.org/10.3928/19382359-20190327-01

Goss, C. H., \& Burns, J. L. (2007). Exacerbations in cystic fibrosis 1: Epidemiology and pathogenesis. Thorax, 62, 360-367. https://doi. org/10.1136/thx.2006.060889

Havermans, T., Colpaert, K., \& Dupont, L. J. (2008). Quality of life in patients with cystic fibrosis: Association with anxiety and depression. Journal of Cystic Fibrosis, 7, 581-584. https://doi.org/10. 1016/j.jcf.2008.05.010

Havermans, T., Colpaert, K., Vanharen, L., \& Dupont, L. J. (2009). Health related quality of life in cystic fibrosis: To work or not to work? Journal of Cystic Fibrosis, 8, 218-223. https://doi.org/10. 1016/j.jcf.2009.03.002

Hayes, A. F. (2017). Introduction to mediation, moderation, and conditional process analysis: A regression-based approach. Guilford publications.

Herriot, H., \& Wrosch, C. (2020). Self-compassion as predictor of daily physical symptoms and chronic illness across older adulthood. Journal of Health Psychology. https://doi.org/10.1177/13591 053211002326

Iancu, I., Bodner, E., \& Ben-Zion, I. Z. (2015). Self esteem, dependency, self-efficacy and self-criticism in social anxiety disorder. Comprehensive Psychiatry, 58, 165-171. https://doi.org/10. 1016/j.comppsych.2014.11.018

Ilies, I. A., Egan, H., \& Mantzios, M. (2019). Comparing state anxiety and mindfulness between mindfulness and loving-kindness meditation whilst controlling for the effect of altruism and boredom. Current Issues in Personality Psychology, 7, 109-119. https://doi. org/10.5114/cipp.2019.85412

Keyte, R., Egan, H., Jackson, C. A., Nash, E., Regan, A., \& Mantzios, M. (2017). A weekend/weekday comparison of adherence to daily treatment regimens in adults with cystic fibrosis. Health Psychology Report. https://doi.org/10.5114/HPR.2018.72331

Keyte, R., Egan, H., \& Mantzios, M. (2019a). An exploration into knowledge, attitudes, and beliefs towards risky health behaviours in a paediatric cystic fibrosis population. Clinical Medicine Insights: Circulatory, Respiratory and Pulmonary Medicine, 13, 1-10. https://doi.org/10.1177/1179548419849427 
Keyte, R., Egan, H., \& Mantzios, M. (2019b). Healthcare professionals' perceptions of risky health behaviours: A qualitative evaluation of preventative measures for populations with cystic fibrosis. Chronic Illness. https://doi.org/10.1177/1742395319856395

Keyte, R., Egan, H., Nash, E. F., Regan, A., Jackson, C., \& Mantzios, M. (2020). An exploration into experiences and attitudes regarding risky health behaviours in an adult cystic fibrosis population. Psychology, Health \& Medicine, 25, 1013-1019.

Knudsen, K. B., Pressler, T., Mortensen, L. H., Jarden, M., Skov, M., Quittner, A. L., Katzenstein, T., \& Boisen, K. A. (2016). Associations between adherence, depressive symptoms and health-related quality of life in young adults with cystic fibrosis. Springerplus, 5, 1216. https://doi.org/10.1186/s40064-016-2862-5

Lovibond, P. F., \& Lovibond, S. H. (1995). The structure of negative emotional states: Comparison of the depression anxiety stress scales (DASS) with the beck depression and anxiety inventories. Behaviour Research and Therapy, 33, 335-343. https://doi.org/ 10.1016/0005-7967(94)00075-U

MacBeth, A., \& Gumley, A. (2012). Exploring compassion: A metaanalysis of the association between self-compassion and psychopathology. Clinical Psychology Review, 32, 545-552. https://doi. org/10.1016/j.cpr.2012.06.003

Mantzios, M., \& Egan, H. (2016). Mindfulness training may enhance the psychological well-being of people with cystic fibrosis. Mindfulness, 7, 781-784. https://doi.org/10.1007/s12671-015-0462-z

Mantzios, M., \& Egan, H. (2017). On the role of self-compassion and self-kindness in weight regulation and health behavior change. Frontiers in Psychology, 8, 229. https://doi.org/10.3389/fpsyg. 2017.00229

Mantzios, M., Egan, H., \& Patchell, C. (2016). Can existing knowledge on eating behaviors and obesity support people with cystic fibrosis who are nutritionally compromised? Frontiers in Psychology, 7, 1477. https://doi.org/10.3389/fpsyg.2016.01477

Neff, K. D. (2003a). The development and validation of a scale to measure self-compassion. Self and Identity, 2, 223-250. https:// doi.org/10.1080/15298860309027

Neff, K. (2003b). Self-compassion: An alternative conceptualization of a healthy attitude toward oneself. Self and Identity, 2, 85-101. https://doi.org/10.1080/15298860309032

Neff, K. D., \& Germer, C. K. (2013). A pilot study and randomized controlled trial of the mindful self-compassion program. Journal of Clinical Psychology, 69, 28-44. https://doi.org/10.1002/jclp. 21923

Phillips, W. J. (2018). Past to future: Self-compassion can change our vision. Journal of Positive School Psychology, 2, 168-190.

Pinto-Gouveia, J., Duarte, C., Matos, M., \& Fráguas, S. (2014). The protective role of self-compassion in relation to psychopathology symptoms and quality of life in chronic and in cancer patients. Clinical Psychology \& Psychotherapy, 21, 311-323. https://doi. org/10.1002/cpp.1838

Platten, M. J., Newman, E., \& Quayle, E. (2013). Self-esteem and its relationship to mental health and quality of life in adults with cystic fibrosis. Journal of Clinical Psychology in Medical Settings, 20, 392-399. https://doi.org/10.1007/s10880-012-9346-8

Priel, B., \& Shahar, G. (2000). Dependency, self-criticism, social context and distress: Comparing moderating and mediating models. Personality and Individual Differences, 28, 515-525. https://doi. org/10.1016/S0191-8869(99)00116-6

Przezdziecki, A., Sherman, K. A., Baillie, A., Taylor, A., Foley, E., \& Stalgis-Bilinski, K. (2013). My changed body: Breast cancer, body image, distress and self-compassion. Psycho-Oncology, 22, 1872-1879. https://doi.org/10.1002/pon.3230

Quittner, A. L., Goldbeck, L., Abbott, J., Duff, A., Lambrecht, P., Solé, A., ... Barker, D. (2014). Prevalence of depression and anxiety in patients with cystic fibrosis and parent caregivers: Results of the international depression epidemiological study across nine countries. Thorax, 69, 1090-1097. https://doi.org/10.1136/thora xjnl-2014-205983

Rajabi, M., \& Ghezelsefloo, M. (2020). The relationship between job stress and job-related affective well-being among English language teachers: The moderating role of self-compassion. Iranian Journal of English for Academic Purposes, 9, 95-105.

Riekert, K. A., Bartlett, S. J., Boyle, M. P., Krishnan, J. A., \& Rand, C. S. (2007). The association between depression, lung function, and health-related quality of life among adults with cystic fibrosis. Chest, 132, 231-237. https://doi.org/10.1378/chest.06-2474

Salzberg, S. (1995). Loving kindness: The revolutionary art of happiness. Shambala.

Sawicki, G. S., \& Goss, C. H. (2015). Tackling the increasing complexity of CF care. Pediatric Pulmonology, 50, S74-S79. https://doi. org/10.1002/ppul.23244

Schmid-Mohler, G., Caress, A. L., Spirig, R., Benden, C., \& Yorke, J. (2019). "Thrust out of normality"-How adults living with cystic fibrosis experience pulmonary exacerbations: A qualitative study. Journal of Clinical Nursing, 28, 190-200. https://doi.org/10.1111/ jocn.14646

Seekis, V., Bradley, G. L., \& Duffy, A. (2017). The effectiveness of self-compassion and self-esteem writing tasks in reducing body image concerns. Body Image, 23, 206-213. https://doi.org/10. 1016/j.bodyim.2017.09.003

Segal, Z. V., Williams, J. M. G., \& Teasdale, J. D. (2002). Mindfulnessbased cognitive therapy for depression: A new approach to preventing relapse. Guilford Press.

Shahar, B., Szepsenwol, O., Zilcha-Mano, S., Haim, N., Zamir, O., Levi-Yeshuvi, S., \& Levit-Binnun, N. (2015). A wait-list randomized controlled trial of loving-kindness meditation programme for self-criticism. Clinical Psychology \& Psychotherapy, 22, 346356. https://doi.org/10.1002/cpp.1893

Sirois, F. M., Molnar, D. S., \& Hirsch, J. K. (2015). Self-compassion, stress, and coping in the context of chronic illness. Self and Identity, 14, 334-347. https://doi.org/10.1080/15298868.2014.996249

Stenekes, S. J., Hughes, A., Grégoire, M. C., Frager, G., Robinson, W. M., \& McGrath, P. J. (2009). Frequency and self-management of pain, dyspnea, and cough in cystic fibrosis. Journal of Pain and Symptom Management, 38, 837-848. https://doi.org/10.1016/j. jpainsymman.2009.04.029

Yohannes, A. M., Willgoss, T. G., Fatoye, F. A., Dip, M. D., \& Webb, K. (2012). Relationship between anxiety, depression, and quality of life in adult patients with cystic fibrosis. Respiratory Care, 57, 550-556. https://doi.org/10.4187/respcare.01328

Zhang, H., Watson-Singleton, N. N., Pollard, S. E., Pittman, D. M., Lamis, D. A., Fischer, N. L., Patterson, B., \& Kaslow, N. J. (2019). Self-criticism and depressive symptoms: Mediating role of self-compassion. OMEGA-Journal of Death and Dying, 80, 202-223. https://doi.org/10.1177/0030222817729609

Publisher's Note Springer Nature remains neutral with regard to jurisdictional claims in published maps and institutional affiliations. 